\title{
A SUSTENTABILIDADE NA PRODUÇÃO RECENTE DE HABITAÇÃO DE INTERESSE SOCIAL
}

\author{
Lara dos Santos Dias*, Silvia Mikami Pina.
}

\section{Resumo}

O objetivo principal desta pesquisa é identificar como a sustentabilidade tem sido introduzida e tratada na produção recente de habitação de interesse social a partir do Programa Minha Casa Minha Vida (PMCMV), criado em 2009 e que têm reorientado suas ações em relação à sustentabilidade recentemente. A motivação da pesquisa se dá pelo interesse em torno da qualidade socioambiental urbana e seus reflexos na vida das pessoas. Neste sentido, são necessários estudos e engajamento teórico para a aplicação de critérios mais consistentes de sustentabilidade nas habitações sociais, buscando soluções mais eficazes e eficientes a fim de minimizar os impactos ambientais, socioculturais e econômicos.

\section{Palavras-chave:}

Habitação Social, Sustentabilidade, Programa Minha Casa Minha Vida.

\section{Introdução}

A recente produção habitacional de interesse social realizada no Brasil é marcada em sua maioria por empreendimentos de baixa qualidade e políticas públicas voltadas para os aspectos quantitativos que podem agravar ainda mais a qualidade de vida urbana. O programa habitacional PMCMV deveria ser oportunidade para incorporar exigências e medidas viáveis para o desenvolvimento sustentável em edificações, mas incorporou poucos requisitos relacionados aos aspectos da sustentabilidade. Em 2017, foram lançados os Cadernos Minha Casa + Sustentável que representam uma agenda de esforços do Sistema Nacional da Habitação para o aprimoramento do PMCMV. Na coleção são apresentados conteúdos que visam contribuir para o desenvolvimento sustentável nos projetos das habitações por meio de diretrizes e recomendações. Desse modo, o objetivo central da pesquisa é identificar se e como tais conteúdos dos cadernos têm sido incorporados na produção recente de habitação e qual seu impacto para a adoção de medidas mais sustentáveis.

\section{Resultados e Discussão}

A partir do estudo das diretrizes e recomendações contidas nos cadernos citados, realizou-se um estudo de caso de empreendimento PMCMV construído em Campinas-SP. Os cinco critérios analisados foram: Conectividade e entorno; Mobilidade Urbana e acessibilidade; Diversidade e morfologia; Sustentabilidade e Sistemas de espaços livres. Para a análise gráfica de cada critério foram desenvolvidos diagramas com os resultados obtidos no estudo de caso e uma tabela síntese com os principais resultados gerais. A figura 1 apresenta o diagrama com os resultados da análise feita para o critério de sustentabilidade e a tabela 1 apresenta um exemplo da síntese dos resultados.

Destaca-se a valorização do sistema de espaços livres, pouco presente nos empreendimentos anteriores. Já a diversidade de tipologias habitacionais pouco avançou, assim como as soluções morfológicas de implantação, que pouco se utilizaram das orientações da criação de microcentralidades e variedade de usos.

Figura 1. Diagrama - exemplo da análise gráfica da sustentabilidade no empreendimento em Campinas.

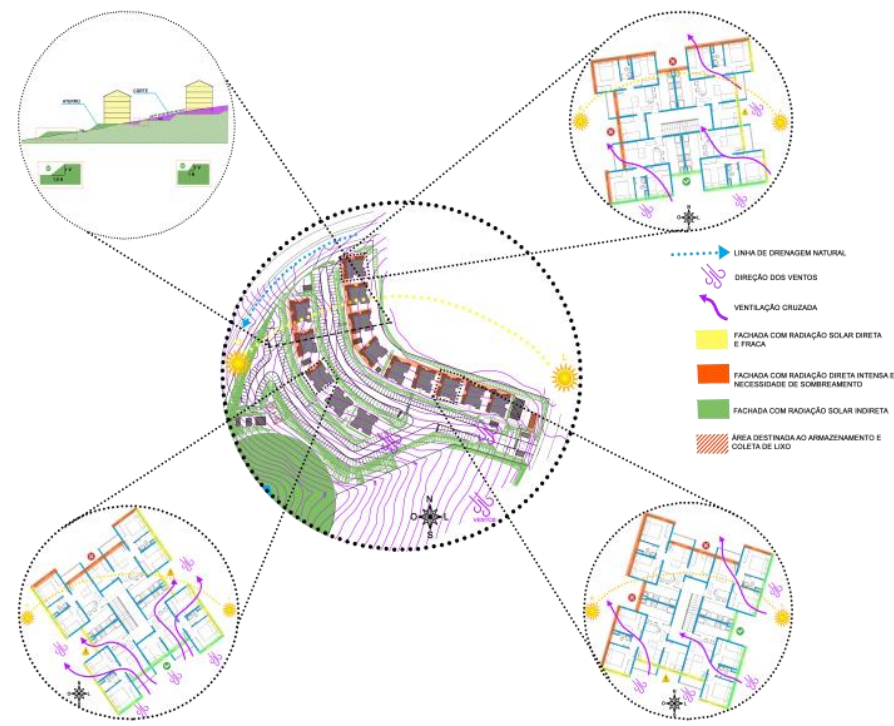

Tabela 1. Tabela síntese dos resultados obtidos.

\begin{tabular}{l|l} 
CRITÉRIOS & RESULTADOS \\
Conectividade e entorno & \\
\hline Mobilidade Urbana e acessibilidade & \\
\hline Diversidade e morfologia & \\
\hline Sustentabilidade & \\
\hline Sistemas de espaços livres & \\
\hline
\end{tabular}

\section{Conclusões}

De forma geral, o empreendimento apresentou avanço na sustentabilidade nos critérios de mobilidade urbana e sistema de espaços livres. No entanto, falhou no quesito de diversidade e morfologia, com raras soluções de medidas sustentáveis. O formato de condomínio fechado adotado parece ser uma tipologia que pouco contribui para a maior sustentabilidade dos empreendimentos. Embora seja um avanço, o PMCMV + sustentável necessita de mais apoio e orientações projetuais aprofundadas para ações efetivas pró-sustentabilidade.

MARICATO, E. Brasil, Cidades: alternativas para a crise urbana. Rio de Janeiro, Editora Vozes, 2001.

Ministério das Cidades / Secretaria Nacional de Habitação - SNH

Caderno 3: diretrizes e recomendações - qualificação do projeto urbano. $1^{\mathrm{a}} \mathrm{ed}$, dez. 2017. 